\title{
SAMUEL BECKETT E A DESISTÊNCIA DIANTE DO TEMPO
}

\author{
Pedro Henrique Trindade Kalil Auad ${ }^{1}$
}

\begin{abstract}
Resumo: Este artigo é uma reflexão sobre o tempo, o teatro e o tempo do/no teatro, se apoiando na obra de Samuel Beckett, mais particularmente de seu texto A Última Gravação. Para tal análise, articularei o tempo da peça do autor irlandês com o conceito imagem-tempo do filósofo francês Gilles Deleuze. Nesse sentido, espera-se esmiuçar o texto de Beckett, seus métodos e história, para provocar uma reflexão incisiva sobre o tempo no teatro e a relação particular do sujeito com o tempo.
\end{abstract}

Palavras-Chave: Samuel Beckett. Tempo no Teatro. Imagem-Tempo. Tempo.

Time is never time at all

You can never ever leave

Without leaving a piece of youth

(The Smashing Pumpkins, "Tonight, Tonight")

Este trabalho propõe uma reflexão sobre o tempo, mais particularmente sobre o tempo no teatro baseado no trabalho de Samuel Beckett, e em seu texto dramático $A$ Última gravação (Krapp's last tape), articulando esta obra com o conceito de imagemtempo de Gilles Deleuze. Beckett é um autor irlandês do século XX que escreveu contos, novelas, poesias, ensaios e textos dramáticos, se tornando conhecido internacionalmente por sua peça Esperando Godot. Sua obra dramática é ligada ao que se convencionou chamar de Teatro do Absurdo a partir da publicação da obra homônima de Martin Esslin. Diferente da grande tradição da filosofia em relação à ideia do absurdo, sobretudo com o existencialismo francês do século XX (época do desenvolvimento dos textos-chaves de Beckett), no Teatro do Absurdo, o absurdo não é apenas o tema apresentado nas peças: o absurdo está na própria forma dramatúrgica. Esslin demarca a diferença entre os autores do Teatro do Absurdo e os filósofos do Absurdo:

O Teatro do Absurdo esforça-se para expressar seu sentido da falta de sentido da condição humana e a inadequação da aproximação racional pela abertura abandonada do artifício racional e do pensamento discursivo. Enquanto Sartre e Camus expressam o novo conteúdo da velha forma convencional, o Teatro do Absurdo vai um passo além tentando atingir uma unidade entre as concepções básicas e a forma na qual elas são expressadas. (ESSLIN, 2004, p. 24).

Aí, forma é tão ou ainda mais importante do que o tema apresentado pelas peças. Léo Gilson Ribeiro também anota essa diferença: Bertolt Brecht, mesmo com as profundas revoluções que provocou no teatro, reproduzia em suas obras uma linguagem

\footnotetext{
${ }^{1}$ Doutor em Teoria da Literatura e Literatura Comparada pela Faculdade de Letras da Universidade Federal de Minas Gerais. E-mail: pedroauad@gmail.com
} 
facilmente reconhecível aos espectadores, encenadores ou dramaturgos. Os "vanguardistas" do absurdo, como chama Ribeiro, tumultuam a linguagem comum, conturbando "o espectador com conceitos e palavras desprovidas de sua acepção normal. Essa linguagem nova e estranha arranca-o do centro de suas associações mentais bitoladas e do aconchego de suas imagens familiares" (RIBEIRO, 1964, p. 137).

Dessa forma, a máxima de Camus - "serei para sempre estranho a mim mesmo" (CAMUS, s/d, p. 32) - não é colocada no palco somente para dizer da estranheza de seus personagens em relação a si, mas para deixar o teatro estranho a si mesmo. Em Dias felizes, Beckett não fala somente sobre o absurdo da incomunicabilidade humana entre os personagens Winnie e Willie, mas toda a cena é colocada de maneira absurda: Winnie está enterrada em um buraco (até a cintura no primeiro ato, até o pescoço no segundo) enquanto seu marido, Willie, também preso em um buraco, rasteja atrás dela.

O absurdo presente na obra de Beckett compartilha muitas características com o que Leda Martins chama de cena total:

\begin{abstract}
O tempo, o espaço e a ação acumulam uma significação única numa totalidade absoluta e compacta. O passado e as causas das transformações tornam-se secundários. Importa a situação em si, independente do que aconteceu ou acontecerá, num tempo e espaço autoreferenciais, emblemas de uma descontinuidade que irrompe no palco e o atravessa vertiginosamente (MARTINS, 1991, p. 69).
\end{abstract}

Percebemos a mesma construção cênica em Beckett. Vejamos o clássico Esperando Godot: Vladimir e Estragon estão sentados em uma estrada, debaixo de uma árvore, e isso é tudo. Não sabemos o que aconteceu antes e o que vai acontecer depois com as personagens (de onde vieram, para onde vão), tampouco quem são esses dois personagens. $\mathrm{O}$ antes e o depois dos acontecimentos da peça, o lugar do acontecimento e as ações dos personagens se acumulam, criando uma significação em si. Isso provoca o desmoronamento de uma estética teatral, facilmente reconhecível, em que o enredo segue uma sequência linear ou lógica.

$\mathrm{Na}$ cena total, o teatro se fecha em si mesmo, criando uma significação própria: o tempo, o espaço e as ações só fazem sentido naquele momento, não existe um antes e um depois formalmente marcados. A cena total não se resume somente ao tema da peça. Tal qual verificamos com a imagem-tempo, ela é uma união entre forma e tema: na cena total podemos verificar uma temporalidade própria que foge ao enredo tradicional da peça teatral, não sendo mais possível verificarmos mais uma sequência linear nos acontecimentos. Formal e tematicamente, as peças de Beckett primam por acontecimentos, gestos e cenografia que se repetem ao infinito, não em uma progressão ou em uma regressão, e que só fazem sentido no momento da ação representada. Com a cena total, percebemos uma temporalidade que, como dito, diverge do teatro tradicional. Mas o que queremos dizer com o tempo tradicional do teatro? Vamos verificar dois olhares críticos a respeito e como Beckett cria um tempo distinto em que a lógica linear não é mais perceptível. 
No tempo teatral, como demonstra Anne Ubersfeld, há duas temporalidades distintas: "a da representação e a da ação representada" (UBERSFELD, 2005, p. 125). O tempo no teatro pode ser compreendido como "a relação entre uma e outra, e que essa relação depende não tanto das respectivas durações da ação representada e da representação" (UBERSFELD, 2005, p. 125), essas relações temporais determinam a significação temporal teatral. Para Ubersfeld, o tempo no teatro não pode ser percebido facilmente nem no texto nem na representação. Ainda, no texto, os significantes temporais não são exatos - a não ser como claramente demonstrados em autores como Beckett ou Ibsen - ou na representação: o ritmo, pausas e articulações são elementos decisivos de difícil percepção, principalmente, porque estamos mais atentos ao espaço cênico do que ao tempo da representação.

No teatro clássico grego, a "boa" peça seria aquela em que o tempo da representação coincidisse com o tempo da ação representada, em uma proporção aproximada de duas horas de espetáculo (o tempo da representação) para um dia, ou vinte e quatro horas na ação representada. Com essa relação, submetia-se o tempo teatral a um tempo histórico, como se o tempo vivido, ou mesmo esse tempo psicológico, pudesse ser mensurável. O tempo no teatro clássico sofre um deslocamento para o extracênico: é a partir do que é falado pelos seus personagens que você descobre acontecimentos passados: o passado é colocado para fora da cena, e ali permanece apenas um conflito que ocorre no presente da representação.

Para o espectador do teatro grego, o tempo psicológico não age, em razão da "homogeneidade entre o tempo vivido pelo espectador e o tempo referencial da narrativa representada" (UBERSFELD, 2005, p. 128), transformando o passado em um passado morto, completo. No Romantismo, o teatro desconstrói essa relação préestabelecida entre o tempo da representação e da ação representada. Quando o teatro encontra a descontinuidade temporal, isso faz com que o espectador crie uma relação entre intervalos: o espectador já não vê o que acontece; ele constrói. É nesse ponto que se tem uma das diferenças entre a dramaturgia clássica grega e as do romantismo em diante.

A representação é um tempo vivido em presença dos espectadores, tempo que será determinado por um grande número de condições socioculturais. A representação é um outro tempo em que acontece uma ruptura com o tempo físico do espectador. $\mathrm{O}$ texto dramático indica, por outro lado, um tempo relatado que não pode ser confundido com o tempo real da representação, mas com um tempo imaginário ou sincopado. Como dito anteriormente, são poucos os autores que no texto dramático indicam o tempo da representação. No caso de Beckett o texto dramático tem explicitamente os elementos determinantes como, por exemplo, em A Última gravação:

KRAPP: [Rápido.] Ah! [Ele levanta sua cabeça e olha à frente. Com contentamento.] Caixa... três... rolo... cinco. [Ele levanta sua cabeça e olha à frente. Com contentamento.] Rolo! [Pausa] Roooolo! [Sorriso feliz. Pausa. Se curva sobre a mesa, começa a espreitar e a bater nas caixas] (BECKETT, 1990, p. 216). 
Essas indicações de Beckett são determinantes para a leitura do texto dramático. Pausas, reticências, indicações de velocidade da representação, ritmo dos diálogos (quando acontecem), são significantes temporais para a leitura. Na representação da peça esses significantes são apresentados ao público. Beckett tende a querer confundir em suas peças, como também em A Última gravação, o momento da ação representada com o momento da representação, transformando a ação representada no eterno momento da representação. Uma imagem mesma, um tempo mesmo, como na cena total, que retorna o tempo sempre a si mesmo.

Podemos também notar os procedimentos de criação dessa ilusão, por Beckett, ao observar as considerações sobre o tempo no teatro de Hans-Thies Lehmann. Para Lehmann, as camadas temporais são os diversos fatores que, mesmo sendo fiéis ao texto, transformam o texto dramático ou sua representação - sendo essas camadas temporais fatores essenciais até o teatro moderno, diferente do acontece no que ele chama de pós-dramático. Lehmann chama a atenção para um determinado momento, a partir do início do modernismo, em que começa a ocorrer uma "crise no drama", desencadeando em uma também "crise do tempo". Um dos autores eleitos por Lehmann com a intenção de tratar da "crise do tempo" foi Samuel Beckett. Essa crise do tempo no teatro é desencadeada por uma quebra no continuum temporal que "se revela como indício da dissolução, ou ao menos da subversão, do sujeito seguro de seu tempo" (LEHAMNN, 2007, p. 297). Beckett apresenta características dessa crise temporal: "períodos de tempo mínimos, lugar único, concentração em um conflito quase que puramente espiritual, com a tendência de supressão de qualquer elemento real que preencha o espaço e o tempo" (LEHAMNN, 2007, p. 299), em que se opera uma "desagregação da unidade temporal e da continuidade. [...] O fluxo do tempo é constantemente interrompido. A consciência se encontra diante de uma multiplicidade temporal que lhe torna impossível fixar-se num ponto que permita uma perspectiva para a recapitulação de sua realidade de vida" (LEHAMNN, 2007, p. 301).

Em A Última gravação, assim como em demais obras de Beckett, essas camadas temporais se dissolvem, sendo essa dissolução que podemos verificar na "crise do tempo". Um tempo que sempre se remete ao presente da representação, não deixando espaço para as diversas camadas temporais. Por isso, a repetição das ações que acontece na obra do dramaturgo irlandês é importante. Na obra dramática de Beckett, ensaia-se de maneira geral, o que Deleuze chama de eterno retorno da diferença, em que "tudo é repetição na série do tempo" (DELEUZE, 2006, p. 157), sendo a repetição "a condição para que algo de absolutamente novo seja efetivamente produzido" (CASTRO, 2007, p. 157).

Para Deleuze, em Diferença e repetição, o que se repete é que vai ser diferente devido à natureza de todas as coisas: a mudança infinita. E mais, só através da repetição é que se transgride:

Se a repetição existe, ela exprime, ao mesmo tempo, uma singularidade contra o geral, uma universalidade contra o particular, um notável contra o ordinário, uma instantaneidade contra a variação, uma eternidade contra a permanência. Sob todos os aspectos, a repetição é a transgressão. (DELEUZE, 2006, p. 21) 
Pode-se dizer que em Beckett há uma crise no tempo do drama à medida que as repetições de ações em suas peças transgridem o próprio tempo teatral, tal como era concebido por alguns autores anteriores a Beckett. A temporalidade no autor irlandês não mais segue uma lógica linear, criado um tempo em que a referência não pode mais ser facilmente reconhecível pelo espectador, a não ser a referência do próprio tempo teatral. O tempo não está mais a serviço do desenvolvimento de uma narrativa linear. $\mathrm{O}$ tempo em Beckett é uma repetição infinita, e aí reside uma novidade: um tempo transgressor em relação ao próprio teatro. A ruptura com a lógica sensório-motora presente na imagem-tempo, também é apresentada por Beckett, em seu teatro absurdo, em que uma cena total é apresentada no palco, com um tempo indefinido, com uma “temporalidade imensurável” (MARTINS, 1991, p. 69).

É essa temporalidade que verificamos em $A$ Última gravação. A peça de Beckett é um monólogo que tem Krapp como personagem principal. Em todos os seus aniversários, Krapp repete o mesmo ato: faz uma gravação sobre sua vida e também escuta uma gravação do passado. Logo no início da peça vemos Krapp em sua caverna. No cenário temos uma mesa com duas gavetas que se abrem em direção ao público. Em cima da mesa vemos um gravador com microfone e caixas de papelão contendo rolos de fitas gravadas. Somente há iluminação na mesa e em sua adjacência imediata: uma luz branca forte. O restante do palco fica na escuridão. Beckett indica nas rubricas características físicas de Krapp: velho, muito míope, voz rachada e de difícil audição e com uma entonação distinta, andar cansado. A vestimenta e o rosto de Krapp são assim descritos: "calças pretas desbotadas e apertadas muito curtas para ele. Paletó preto desbotado sem mangas, quatro amplos bolsos. [...] Camisa branca suja aberta no pescoço, sem colarinho. Face branca. Nariz violeta. Cabelo cinza bagunçado. Barba por fazer" (BECKETT, 1990, p. 215).

No início do texto Krapp realiza ações aparentemente sem sentido:

\begin{abstract}
Krapp fica um momento parado, tem um grande suspiro, olha para seu relógio, remexe os bolsos, pega um envelope, coloca de volta, remexe, pega um pequeno molho de chaves, leva a seus olhos, escolhe uma chave, escolhe uma chave, se levanta e se move para frente da mesa. Ele se inclina, abre a primeira gaveta, olha dentro dela, sente o que tem dentro, pega um rolo de fita, a olha, coloca de volta, fecha a gaveta, abre a segunda gaveta, olha dentro dela, sente o que tem dentro dela, pega uma grande banana, olha para ela, fecha a gaveta, põe a chave de volta no bolso. (BECKETT, 1990, p. 215)
\end{abstract}

A partir da aparência de Krapp e de suas ações podemos ver melhor a "sua vida solitária, vazia, preenchida por irrisórios movimentos" (BARRENTINI, 2004, p. 136), antes mesmo de ele começar a ouvir as gravações.

Depois de muitas ações sem sentido aparente, Krapp coloca uma fita no gravador, se coloca em postura de escuta e começa a ouvir a gravação. Como indica Beckett, a gravação tem "uma voz forte, de preferência pomposa, claramente é Krapp muito mais jovem" (BECKETT, 1990, p. 217). A partir daí, acontece a insólita conversa entre Krapp e o gravador, entre o velho Krapp e o jovem Krapp gravado. Krapp mal se reconhece na gravação, muitas vezes precisa de um dicionário para entender $o$ significado de algumas palavras que são ditas pelo gravador. Krapp é um estranho a si mesmo. 
Podemos verificar ao menos três Krapps distintos em A Última gravação: o Krapp velho presente no palco, a fita com a gravação de Krapp mais jovem e um Krapp ainda mais jovem, a quem a gravação remete. Na gravação podemos ver o personagem comentando uma gravação ainda mais antiga, da qual se recorda com ironia: "Difícil de acreditar que eu fui esse jovem. A voz! Jesus! E as aspirações! [...] E as resoluções! [...] Beber menos, em particular" (BECKETT, 1990, p. 218). A reação do velho Krapp em relação à gravação deixa de ser irônica para se tornar enfática: "Escutando esse bastardo estúpido que fui trinta anos atrás, difícil de acreditar que fui tão ruim quanto aquilo" (BECKETT, 1990, p. 215).

Assim, vemos que existe em A Última gravação uma aparente ordenação temporal (passado-presente-futuro). Porém, como dito, o que vemos em todas as obras de Beckett são "tipos de situações que se repetirão eternamente" (ESSLIN, 2004, p. 63). Por mais que tenhamos três Krapps distintos temporalmente, o que vemos, na verdade, é Krapp repetir eternamente as mesmas situações: todos os anos, em seu aniversário, Krapp escuta uma gravação antiga e repudia a mesma. Por mais que Krapp não se reconheça na gravação, por mais que seja uma pessoa diferente daquele tempo passado (presente na gravação que escuta), ele ainda é o mesmo. Isso se torna claro no final da peça. Krapp move os lábios, mas o som que aparece no palco é o som da gravação:

[Pausa. Os lábios de KRAPP se movem. Sem som.]

FITA: Passada a meia-noite. Nunca conheci tamanho silêncio. A terra deve estar inabitada. [Pausa.]

Aqui eu termino este carretel. Caixa - [Pausa.] - três, rolo - [Pausa.] - cinco. [Pausa.] Talvez meus melhores anos tenham se esvaído. Quando tinha uma chance de felicidade. Mas eu não os quereria de volta. Não com o fogo em mim agora. Não, eu não os quereria de volta. (BECKETT, 1990, p. 223)

Neste ponto, o texto de Beckett embaralha Krapp e a gravação. Um é o presente e o outro a voz desse presente - o tempo, nesse sentido, é um eterno presente, mas se ramifica em temporalidades diversas: do presente do palco, tem-se o passado da gravação, e da gravação a outro passado ainda mais distante. Entretanto, essas ramificações estarão para sempre inscritas no presente, tornando-se eterna a presentificação das repetições, uma ação que só faz sentido naquele momento. Beckett cria a ilusão de unir o tempo da ação representada com o da representação, ligando o tempo da ação representada de sua peça ao momento da representação teatral: o teatro "é o que por natureza nega a presença do passado e do futuro" (UBERSFELD, 2005, p. 132).

Essa ilusão temporal criada por Beckett é ainda reforçada pela construção da memória do protagonista. Krapp é também um escritor, com "dezessete cópias vendidas, das quais onze a preço de custo para bibliotecas de livre circulação além-mar” (BECKETT, 1990, p. 222). Krapp poderia ter simplesmente escrito um anuário sobre as realizações do ano que passou e reler um anuário do passado. Se isso acontecesse, Krapp daria voz ao seu passado - ele seria ele mesmo, não o "diferente que é o mesmo" de uma gravação em que ele mal se reconhece. O gravador tem uma função fundamental no texto de Beckett. O gravador faz com que, como afirma John Fletcher, 
Krapp "tenha algum tipo de ligação com o passado, que a memória sozinha é incapaz de recapturar, Beckett dá a uma máquina a função que Proust caracterizou como uma faculdade misteriosamente humana" (FLETCHER, 1971, p. 74).

A memória de Krapp é falha, depende de uma máquina para que ele recorde seu passado (e mesmo assim não o reconhece integralmente). A memória não é ativada voluntariamente, portanto é uma memória involuntária e forçada. Através dessa memória forçada é que Krapp reconhece um passado feliz que viveu ao lado de uma mulher. A ativação da memória, que seria natural do humano, é entregue à máquina e só é ativada depois de uma "força não-natural".

Ao rememorar a vida que viveu ao lado da mulher, Krapp e a gravação se encontram novamente em repetição: primeiro negam a vida do jovem, a "idiotice" do amor declarado e do romantismo. Depois, ambos se questionam se essa época da vida não foi a melhor que tiveram e são invadidos pela nostalgia. Esse questionamento vem seguido de negação, como vemos no final da peça: talvez os melhores anos já tenham passado, mas não os quer de volta. A memória, tal qual a ilusão do tempo, funciona como um meio de criar a sensação de presentificar a ação representada. Não se retorna ao passado, ele não é reconstituído paralelamente no tempo da ação dramática, com o uso de um flash-back, por exemplo. Essa memória irrompe no presente, encontra Krapp por duas vezes (no palco e na gravação), mas a chance de revivê-la é recusada. Krapp não se envolve com o passado, apenas questiona a felicidade que teria tido e, mesmo assim, não tem certeza se foi feliz.

É importante ressaltar que a repetição dos acontecimentos acontece no palco. Como dito antes, o palco tem uma iluminação simples: uma luz branca e forte ilumina a mesa onde fica o gravador e suas adjacências, o resto do palco está escuro. Krapp permanece quase todo o tempo na parte clara do palco. Em alguns momentos Krapp desloca-se para escuridão, como quando busca um dicionário para saber o significado da palavra "viúvo". O contraste entre o claro e o escuro é explicado pelo próprio Beckett: "a morte está constantemente atrás dele [...] e inconscientemente ele está olhando para isso [para a escuridão] porque é o fim" (BECKETT, apud FLETCHER, 2000 , p. 133). Uma forma dramática dicotômica, no caso o claro/escuro e a vida/morte, é rara em Beckett.

Porém, essa aparente dicotomia adquire uma força dramática. Antes de Krapp começar a ouvir a gravação, ele se retém em uma expressão: “...Hm....memorável... o que? [Ele olha mais de perto.] Equinócio, equinócio memorável. [Ele levanta sua cabeça, olha para frente inexpressivamente. Surpreso.] Equinócio memorável?... [Pausa. Dá de ombros, olha mais de perto o livro, lê.] Adeus ao - [ele muda a página] - amor" (BECKETT, 1990, p. 217). O equinócio refere-se ao momento do ano em que a duração do dia é igual à duração da noite.

Krapp desconhece e "dá de ombros" para o significado de equinócio memorável. É como se as dicotomias (vida e morte; claro e escuro; corpo e alma) não fossem perfeitas, exatas, tal qual o equinócio faz com o dia e com a noite. Se a dicotomia é impossível, logo ela não é importante. Não é descartável a frase seguinte de Krapp: "Adeus ao amor" (Farewell to love). Farewell to love é o nome de uma obra do poeta metafísico John Donne, do século XVII. Este é um poema sobre a desistência de um 
amante em relação à pessoa amada. Nele também temos a dicotomia entre o claro (summer's sun) e o escuro (shadows). Entretanto, a sombra, o escuro, é o lugar para onde se vai quando tudo mais falhar. A sombra é o refúgio. O que nenhum homem pode encontrar? $\mathrm{O}$ amor, aparentemente, mas uma união entre o amor carnal e o amor que vive na alma. O poema é recheado de palavras com duplo sentido: seed (semente, mas também esperma), heat (calor, paixão, excitação sexual), dote (amar cegamente e também caducar). Esse duplo sentido é uma forma de buscar encarnar, em uma só palavra, a matéria e o espírito.

Krapp também vive esse dilema: a relação sexual em um barco, o possível amor presente naquela relação, a desistência de apostar na felicidade nostálgica oriunda dessas relações. O equinócio, palavra que Krapp não reconhece, é desconsiderado, tamanha a impossibilidade da união perfeita, pura. Porém, se tudo o mais falhar, existe a sombra. Se tudo para Krapp falhar, naquela luz, com aquele gravador, ele tem a sombra atrás dele, a morte. Krapp pode desistir.

Beckett constrói de forma astuta toda a imagem cênica que sustenta $A$ Última gravação: um tempo que se constrói de forma a retornar, sempre, ao momento da representação, criando a ilusão entre a ação representada e a representação, uma memória que fortalece o eterno presente, com um palco em claro e escuro, de forma dicotômica. Entretanto, o que vemos no palco é uma falsa dicotomia, ou ainda, uma dicotomia é instaurada apenas para sabermos que dicotomias equilibradas são irreconhecíveis ou impossíveis (como o equinócio).

A imagem cênica construída em A Última gravação corrobora o próprio pensamento que Beckett traça a respeito da arte. Em Three dialogues, Beckett expõe o seu ideal de arte e de imagem, a partir das pinturas do holandês Bram Van Velde. Beckett reconhece que, através da obra do pintor, percebemos que "a expressão é um ato impossível" (BECKETT, 2006, p. 556), e que, diante disso, nada podemos fazer, a não ser expressar a impossibilidade: a arte se torna uma "fidelidade à falha, uma nova ocasião, uma nova relação, e ao ato em que, incapaz de atuar, obrigado a atuar, ele faz, um ato expressivo, mesmo que só dele mesmo, de suas impossibilidades, de suas obrigações" (BECKETT, 2006, p. 562).

Essa fidelidade à falha é a forma que Beckett encontra para superar um dos desafios primordiais da arte: a unificação entre o corpo e o espírito. Sabendo da impossibilidade de "superar a fratura metafísica da presença" (AGAMBEN, 2007, p. 214), Beckett reconhece em Van Velde o pintor que, ao perceber a falha, a fratura, desiste, mas essa desistência é uma forma de expressão - porque não tem por que se expressar. O mesmo movimento que acontece em Bartleby, de Melville: "I would prefer not to" - a frase agramatical de alguém que desiste e, ao mesmo tempo, insiste.

Nas pinturas de Van Velde não temos mais a tentativa de ligar a dicotomia representante e representado. Como Beckett, Van Velde faz em várias de suas pinturas e litografias contrastes entre claro e escuro. Jean Galard afirma que a unificação dos contrários é "uma tarefa essencial da arte" (GALARD, 2008, p. 81). O claro e o escuro da litografia de Van Velde não podem ser apontados como uma dicotomia, pois o pintor holandês já não pretende a união dos contrários. 
Quando Beckett coloca Krapp trafegando entre o claro e o escuro em A Última gravação, apresenta a dicotomia como uma impossibilidade. Krapp não se importa e não faz diferença para ele transitar entre o claro (lugar com iluminação) e o escuro (sem iluminação). Krapp é um personagem que desistiu. Krapp, por sinal, tem um nome muito sugestivo: crap em inglês significa sujeira, "bosta" (em um sentido pejorativo de fezes), besteira e também é o verbo "cagar" (também com sentido pejorativo). Krapp é ainda mais "sujo" quando colocado diante da máquina: a máquina é mais humana do que Krapp. Os movimentos e as falas de Krapp são todas pausadas, frases curtas, constantemente interrompidas por movimentos, muitas vezes, aleatórios: "Deixa isso para lá! Jesus! Tira sua mente do seu dever de casa! Jesus (Pausa. Cansado.) Ah bem, talvez ele esteja certo. (Pensa. Entende. Desliga. Consulta o envelope. Pah! (O dobra e joga fora. Pensa. Liga.)" (BECKETT, 1990, p. 215), enquanto o gravador tem falas articuladas, voz forte, quase sem pausas ou movimentos descontínuos: "A semente, agora eu me pergunto o que eu queria dizer com isso, eu quero dizer... (hesita)... Eu acho que quero dizer que essas coisas valem à pena ter quando toda a poeira tenha - que toda a minha poeira tenha baixado. Eu fecho meus olhos e tento e as imagino" (BECKETT, 1990, p. 215).

Dessa forma, Krapp é um anti-herói nato. A união entre o sublime e o grotesco pregado por Victor Hugo (2007) em relação aos protagonistas da literatura na consolidação da modernidade, ou seja, os personagens do Romantismo são praticamente descartados. Krapp é o resto, nem mesmo em seu nome é utilizada uma palavra "nobre" para fezes: é Crap, a forma vulgar do inglês. O sentido histórico aqui tem importância. $\mathrm{Se}$, com o modernismo da arte, os valores tradicionais começam a ser questionados, na segunda fase da modernidade artística, dos anos 50 aos anos 70 do século XX, valores tradicionais artísticos são quase completamente abandonados.

A combinação do pós-guerra em termos artístico-filosóficos é extremamente interessante: existencialismo francês, arte abstrata americana e o Teatro do Absurdo. Deleuze indica outra informação importante no cinema: o surgimento da imagemtempo. Por mais que esses pensamentos sejam, de certa forma, independentes, eles se fazem presentes em Beckett. Como dito antes, o existencialismo francês é uma das escolas filosóficas que mais pensaram e discutiram a respeito do absurdo, o que é refletido no Teatro do Absurdo. O que Beckett encontra em Bram Van Velde também pode ser notado no abstracionismo americano: a pintura abstrata através de um esforço extraordinário foi capaz de "arrancar a arte moderna da figuração" (DELEUZE, 2007, p. 19). Com todas essas ideias correlatas, vemos que Beckett percebia bem a sua contemporaneidade. A imagem que Beckett cria em A Última gravação, uma cena total e absurda, através de um tempo que ilude a presentificação das ações, de uma memória falha, de uma "falsa" dicotomia, de um anti-herói sujo e vulgar, possui elementos da imagem-tempo apresentada por Deleuze.

A ilusão causada pela presentificação do tempo que acontece na peça faz com que a imagem do passado se una à imagem do presente. Em outras palavras, a imagem virtual do passado se une, em um circuito mínimo, com a imagem do presente. $\mathrm{O}$ tempo como um eterno presente aparece como uma imagem-cristal, na qual somos capazes de senti-lo. A memória entregue à máquina tem uma função fundamental: separa a 
memória de Krapp do próprio Krapp. Vemos que a memória não tem como função recontar o passado para explicar o que aconteceu com aquele velho. A memória contida na gravação funciona como potencializadora do eterno retorno da diferença (para que Krapp esteja para sempre repetindo o mesmo ato, repetindo, mas sempre de uma forma diferente).

Coincidência ou não, Krapp também é, em alemão, o nome de uma espécie de flor: a Rubia tinctorum. A curiosidade dessa planta é que ela é pequena, tendo de 5-10 centímetros, mas se ramifica, crescendo dos mais finos ramos às flores. A sua raiz atinge até um metro. Os únicos animais que comem essa planta são larvas. Não é difícil imaginar uma relação simbólica para essa planta: o tempo presente é curto e se ramifica, em rizomas. A raiz, como o passado ou como a memória, é muito maior que a planta (o presente), mas está enterrada e não podemos vê-la. O que resta é nos alimentarmos do presente, como larvas. Não é difícil imbuir nessa imagem o que Deleuze (2005) identifica na imagem-tempo com suas pontas do presente, lençóis do passado. A imagem do presente está instaurada em A Última gravação, e o passado vai surgindo de uma forma que não se vê, mas que toma uma dimensão muito maior do que o presente.

Dessa forma, a "falsa" dicotomia entre claro e escuro presente no palco não é uma montagem, uma montagem paralela ou por contraste como vemos, por exemplo, em Eisenstein. A "falsa" dicotomia está presente no palco demonstrando a impossibilidade da união corpo e alma, representante e representado. E Krapp, preso na repetição interminável de acontecimentos em um presente que se identifica com o palco, sem memória própria, impossibilitado de unir seu corpo à sua alma, é um homem incapaz de agir, é incapaz de dizer, sendo um personagem que se tornou totalmente passivo em relação ao mundo: por isso seus movimentos aleatórios, sua fala truncada e sem sentido.

$\mathrm{Na}$ imagem-tempo temos esse personagem passivo diante das situações. Beckett apresenta em A Última gravação um personagem totalmente passivo em relação ao tempo. Krapp é quase um vampiro - encontra a eternidade na sombra do palco, mas se convalesce na luz, perto da gravação. Não existe escapatória para Krapp em relação ao tempo. O tempo é um inimigo cruel, invencível. Krapp nada pode fazer: desiste.

Em uma cena total, Beckett constrói uma imagem-tempo, na qual não se tem mais o que fazer a não ser desistir e se entregar à "danação e salvação" (BECKETT, 2003, p. 9) do tempo. Beckett entende isso: ao final da peça nada mais podemos fazer do que observar Krapp por um instante, com a sombra tomando conta do palco e a iluminação ficando somente na luz do gravador. Diante dessa imagem imóvel enfrentamos o verdadeiro sentido do tempo na peça e vemos a imagem-tempo: o tempo fixado eternamente no presente, com imagens virtuais do passado que se ligam ao que acabamos de ver. Não há mais uma lógica sensório-motora e já não podemos compreender de maneira lógica tudo que nos é apresentado; o absurdo da vida, o absurdo de se viver dentro do tempo é instaurado no palco e nada mais podemos fazer além de sentir o tempo. 
ABEL, Lionel. Metateatro: uma visão nova da forma dramática. Trad. Bárbara Heliodora. Rio de Janeiro: Zahar Editores, 1968.

AGAMBEN, Giorgio. Estâncias. Trad. Selvino José Assmann. Belo Horizonte: Editora UFMG, 2007. BARRENTINI, Célia. Samuel Beckett: escritor plural. São Paulo: Perspectiva, 2004.

BECKETT, Samuel. Three dialogues. In: The Grove Centenary Edition: IV Poems Short Fiction Criticism. Nova Iorque: Grove Press, 2006.

BECKETT, Samuel. Proust. Trad. Arthur Nestrovski. São Paulo: Cosac \& Naify, 2003.

BECKETT, Samuel. Krapp's last tape. In: The complete dramatic work. Londres: Faber \& Faber, 1990.

CAMUS, Albert. O Mito de Sísifo. Lisboa: Livros do Brasil, s/d.

CASTRO, Cláudia Maria de. Deleuze, Hölderlin, e a cesura do tempo. O que nos faz pensar: cadernos do departamento de filosofia PUC-Rio, v. 21, p. 145-160, maio 2007.

DELEUZE, Gilles. Cinema II: Imagem-tempo. Trad. Eloisa de Araujo Ribeiro. São Paulo: Brasiliense, 2005.

Diferença e repetição. Trad. Luiz Orlandi e Roberto Machado. São Paulo: Graal, 2006.

. Francis Bacon: lógica da sensação. Trad. Roberto Machado. Rio de Janeiro: Jorge Zahar Editor, 2007.

ESSLIN, Martin. The Theatre of the Absurd. Nova Iorque: Vintage Books, 2004.

FLETCHER, Jonh. Samuel Beckett's art. Londres: Chatto \& Windus, 1971.

FLETCHER, Jonh. Samuel Beckett. Londres: Faber \& Faber, 2000.

GALARD, Jean. A Beleza do gesto. Trad. Mary Amazonas Leite de Barros. São Paulo: Edusp, 2008.

HUGO, Victor. Do grotesto e do sublime. São Paulo: Perspectiva, 2007.

LEHMANN, Hans-Thies. Teatro pós-dramático. Trad. Pedro Süssekind. São Paulo: Cosac \& Naify, 2007.

MARTINS, Leda Maria. O Moderno teatro de Qorpo-Santo. Belo Horizonte: Editora UFMG / UFOP, 1991.

RIBEIRO, Léo Gilson. Cronistas do absurdo. Rio de Janeiro: José Alvaro Editor, 1964.

UBERSFELD, Anne. Para ler o teatro. São Paulo: Perspectiva, 2005.

\section{Recebido em 22/09/2014. Aprovado em 29/10/2014.}

Title: Samuel Beckett and the withdrawal on time

Abstract: This paper is a reflection about time, the theater and the time of/in theater, relying on the work of Samuel Beckett, more particularly of his work Krapp's Last Tape. For this analysis, I will articulate the work of the Irish author with Gilles Deleuze's concept of time-image. In this sense, it is expected to scrutinize the text of Beckett, his methods and history, to bring an incisive reflection on time of the theater and the particular relation of humans and time.

Keywords: Samuel Beckett. Theatre Time. Time-Image. Time. 
